Discussion Paper No. 897

\title{
THE LONG-TERM IMPACT OF THE 1995 HANSHIN-AWAJI EARTHQUAKE ON WAGE DISTRIBUTION
}

\author{
Fumio Ohtake \\ Naoko Okuyama \\ Masaru Sasaki \\ Kengo Yasui
}

\begin{abstract}
April 2014
The Institute of Social and Economic Research Osaka University

6-1 Mihogaoka, Ibaraki, Osaka 567-0047, Japan
\end{abstract}




\title{
The Long-term Impact of the 1995 Hanshin-Awaji Earthquake on Wage Distribution ${ }^{\dagger}$
}

\author{
Fumio Ohtake $^{1}$, Naoko Okuyama ${ }^{2}$, Masaru Sasaki $^{3}$, Kengo Yasui ${ }^{4}$
}

March 30, 2014

\begin{abstract}
This paper explores the effects of the 1995 Hanshin-Awaji Earthquake on the wages of people in the area of the earthquake over the 17 years after its occurrence and identified which part of the wage distribution has been most affected by this event by comparing the wage distributions of disaster victims and non-victims. To do this, we used three decomposition methods, developed by (i) Oaxaca (1973) and Blinder (1973); (ii) DiNardo, Fortin, and Lemieux (1996) ("DFL"); and (iii) Machado and Mata (2005) and Melly (2006). Our findings are as follows. First, the Oaxaca and Blinder decomposition analysis shows that the negative impact of the earthquake still affects the mean wages of male workers. Second, the DFL decomposition analysis shows that middle-wage males would have earned more had the 1995 Hanshin-Awaji Earthquake not occurred. Finally, the Machado-Mata-Melly decomposition analysis shows that the earthquake had a large, adverse impact on the wages of middle-wage males, and that their wages have been reduced since the earthquake, by $5.0-8.6 \%$. This result is similar to that from the DFL decomposition analysis. In the case of female workers, a long-term negative impact of the earthquake was also observed as the wages of high-wage females were reduced by $8.3-13.8 \%$.
\end{abstract}

JEL Classification: J31, Q54

Keywords: Natural disasters, Wage distribution, Wage decomposition, Earthquake

\footnotetext{
${ }^{\dagger}$ Acknowledgments: We thank William DuPont, Lena Edlund, Timothy Halliday, Takahiro Ito, Takao Kato, Daiji Kawaguchi, Peter Kuhn, Edward Lazear, Colin McKenzie, Hideo Owan, Hugh Patrick, Kei Sakata, Till Von Wachter, David E. Weinstein, and the seminar participants at the Columbia Business School, the $27^{\text {th }}$ European Society for Population Economics Conference, the Graduate Center of the City University of New York, the Japanese Economic Association 2013 meeting, and the $6^{\text {th }}$ Trans-Pacific Labor Seminar for helpful conversations and comments.

${ }^{1}$ ISER, Osaka University

${ }^{2}$ Graduate School of Economics, Kobe University

${ }^{3}$ Graduate School of Economics, Osaka University, and IZA

${ }^{4}$ Faculty of Economics, Ritsumeikan University, 1-1-1 Noji-higashi, Kusatsu, Shiga 525-8577, Japan; yasui@fc.ritsumei.ac.jp
} 


\section{Introduction}

It has been 3 years since an earthquake of an unprecedented scale with an epicenter off the coast of the northern part of Japan occurred at 14:46 on March 11, 2011. During the past 3 years, we have wondered how long it would take Japan and the northeastern area (the Tohoku area in Japanese), in particular, to recover from this devastating Great East Japan Earthquake. These questions remain. Not only did the earthquake turn the Tohoku area into rubble, but the resulting tsunami also damaged infrastructure and facilities along the Pacific coastline of the northern part of Japan-and, in particular, the Fukushima No. 1 nuclear power plant. ${ }^{1}$ It is well known that the tsunami triggered core meltdowns in three of that power plant's reactors.

Although 3 years have passed since the Great East Japan Earthquake, the disaster areas are still in the process of being restored and reconstructed. Although it appears that post-quake reconstruction is progressing in the Tohoku area, it will take a significant amount of time for the area to be fully restored to its pre-earthquake level: in particular, housing projects have not progressed as quickly as victims living in temporary housing had expected. Many tsunami victims still cannot return to their houses located in the designated nuclear decontamination areas near the Fukushima No. 1 nuclear plant. The Tokyo Electric Power Company (TEPCO) and the victims are deadlocked on the issue of compensation. On the one hand, the disaster destroyed many jobs in the manufacturing, service, and marine product processing sectors, but, on the other hand, many jobs have been created in the construction sector since the quake. This

\footnotetext{
${ }^{1}$ According to the Japanese National Police Agency, the death toll stood at 15,884 persons and another 2,633 were still missing as of March 10, 2014. The Reconstruction Agency announced that 267,419 evacuees still lived in temporary housing and accommodations as of February 13, 2014. The Agency also reported that the quake-related death toll, including suicides, stood at approximately 3,000 victims. According to the Japanese Government's Cabinet Office, the annualized nominal GDP was JPY 481.1 trillion in the fourth quarter of 2013, still lower than that of the fourth quarter of 2010, just before the earthquake occurred.
} 
generates an employment mismatch problem, and the construction sector suffers from a serious shortage of manpower. From a short-term perspective, the earthquake and subsequent events have left the disaster victims facing financial and physical hardships. However, what about the longer-term perspective? It is thus important to investigate when this hardship is likely to end and how the disaster victims can be assisted to return to their normal lives.

Because only 3 years have elapsed since the Great East Japan Earthquake, it is too early to evaluate its devastating impact from a long-term perspective. Instead, we examine the long-term impact of the Hanshin-Awaji Earthquake of 1995 as a proxy evaluation of the Great East Japan Earthquake. Similar to the Great East Japan Earthquake, this earthquake inflicted devastating damage on the Hanshin area, between the major cities of Osaka and Kobe, which was densely populated and largely industrialized. By assessing the negative impacts of the 1995 Hanshin-Awaji Earthquake from a long-term perspective, this paper aims to investigate to what extent the negative impacts of the earthquake had continued unsolved or had been attenuated at the time of our survey in 2012. This may assist development of a long-term vision relevant to the reconstruction following the Great East Japan Earthquake.

Several studies have analyzed the effects of natural disasters on people's lives, in economic and mental terms. Notably, Ohtake et al. (2012) estimate the long-term impact of the Hanshin-Awaji Earthquake on annual income and amount of social capital relating to interactions with neighbors and friends, using the same online survey data that we also analyzed here. They explored how the earthquake adversely affected the current level of subjective well-being of the disaster victims through a reduction in annual income and deterioration in social capital. More specifically, a disaster victim 
whose house partially or completely collapsed or was destroyed by fire because of the earthquake would have earned additional annual income as at 2011 had the earthquake not occurred. The earthquake also resulted in the deterioration of social capital relating to social interactions. Moreover, these levels of social capital have not yet been fully restored-in particular, the loss of social capital measured by the degree of an individual's interaction with his/her neighbors. The decrease in annual income and the deterioration in social capital were found to have reduced the subjective well-being of the disaster victims.

Our paper differs from previous studies in that it focuses particularly on how large-scale natural disasters, such as the Hanshin-Awaji Earthquake, affect changes in the wage distribution of disaster victims versus non-victims who were engaged in work from the time when the earthquake occurred in 1995 to the time the survey was conducted in 2012. We paid particular attention to which part of the wage distribution was most negatively affected by the 1995 Hanshin-Awaji Earthquake.

The objectives of this paper are to explore how the Hanshin-Awaji Earthquake affected the wage distribution during the 17 years after its occurrence and to identify who has incurred the largest wage loss: low-wage, middle-wage, or high-wage victims, in comparison with non-victims. In this paper, we used three decomposition methods: those proposed by i) Oaxaca (1973) and Blinder (1973); ii) DiNardo, Fortin, and Lemieux (1996) (“DFL”); and iii) Machado and Mata (2005) and Melly (2006).

Many people probably share the conventional view that low-wage workers would be most vulnerable to natural disasters and would thus conclude that the Hanshin-Awaji Earthquake had the most adverse impact on workers in the lowest percentiles of the wage distribution during the 17 years after its occurrence. However, it 
is important to also explore whether high-wage or middle-wage workers suffered economically from this natural disaster.

In this paper, the case of the 1995 Hanshin-Awaji Earthquake is analyzed with the intention of being able to better forecast the long-term structural changes that may occur in areas destroyed by the Great East Japan Earthquake in 2011. However, there are some limitations to using the Hanshin-Awaji Earthquake case. First, the two earthquakes differed in terms of the subsequent disasters. Although the Hanshin-Awaji Earthquake caused fires that destroyed many houses, the Great East Japan Earthquake created a 15-meter tsunami and the nuclear plant incident. Second, the disaster areas destroyed by the two earthquakes differed in their industrial characteristics. Whereas the Hanshin-Awaji Earthquake damaged mainly a manufacturing and services industries region, the Great East Japan Earthquake devastated a region where the majority of workers were employed in the fishery and agricultural industries. Finally, the disaster areas differ in terms of the population distribution by age. There was a relatively large older population in the Tohoku area when the Great East Japan Earthquake struck, whereas there was a relatively large younger population in the Hanshin area in 1995.

However, analyzing the Hanshin-Awaji Earthquake also has two advantages. The first is that this analysis allows us to examine the long-term impact of an earthquake on people's lives. Moreover, in terms of the scale of the natural disaster, the Hanshin-Awaji Earthquake was similar to the Great East Japan Earthquake. This will enable us to better predict the long-term effects of the Great East Japan Earthquake on the wage structure and income inequalities in the disaster area. In terms of the second advantage, our paper contributes to the existing literature because, to our knowledge, this is the only reported study that empirically analyzes the long-term effects of a 
natural disaster on the wage distribution. Although many empirical studies have analyzed the economic effects of natural disasters, most have focused on how natural disasters affect economic growth or consumption behavior at the aggregate level. The effects of natural disasters on the labor market have rarely used micro data. In this regard, our analysis of the relationship between the earthquake and the wage distribution may provide a foundation for future studies assessing the impact of natural disasters on the accumulation of human and health capital.

We used an Internet survey to collect original data from victims and non-victims in the disaster area of the Hanshin-Awaji Earthquake and on persons living in several selected non-disaster areas at the time of the Hanshin-Awaji Earthquake. The survey was conducted in March 2012. Because natural disasters are usually considered to be unexpected exogenous shocks, we can conduct a unique natural experiment and then identify the exact impact of the natural disaster by comparing outcomes between a treatment group and a control group. We defined the disaster victims as the treatment group, whereas the control group consisted of both non-victims from the disaster area and persons from the selected non-disaster areas.

The main findings can be summarized as follows. First, according to the Oaxaca and Blinder decomposition analysis, the 1995 Hanshin-Awaji Earthquake continues to have a negative impact on the mean wages of male workers 17 years after the earthquake. However, its effect on the mean wages of female workers has disappeared. Second, the DFL decomposition analysis indicated that middle-wage male workers would have earned more had the 1995 Hanshin-Awaji Earthquake not occurred. That is, middle-wage male workers were the most severely affected by the earthquake. In contrast, this was not true for female workers. Finally, the Machado-Mata-Melly 
decomposition analysis also showed that the earthquake had a large, negative effect on the wages of middle-wage males, and that their wages have been lower since the earthquake, by $5.0-8.6 \%$. This result is similar to that of the DFL decomposition analysis. The negative impact of the 1995 earthquake on the wages of high-wage female workers, a 8.3-13.8\% reduction, was still evident in 2011.

The remainder of the paper is organized as follows. We begin with a literature review in Section 2 and then provide a brief overview of the 1995 Hanshin-Awaji Earthquake in Section 3. We discuss the econometric specification in Section 4 and then describe our original data set in Section 5. Subsequently, we present the estimated results in Section 6 and discuss the interpretation of the results in Section 7. The final section provides some concluding remarks.

\section{Literature Review}

This section provides a literature review of research papers relevant to the analysis of the impacts of natural disasters. ${ }^{2}$ We begin with a review of the literature on the short-term impacts of natural disasters. Raddatz (2007) and Noy (2009) first estimated the impacts of natural disasters from a short-term perspective, regressing per capita GDP on the scale of natural disasters. Both authors found the same result, indicating that natural disasters had a negative impact on the economy of the disaster areas in the short term. Noy (2009) added interaction terms with each country's economic and political characteristics and a natural disaster term as explanatory variables and then re-estimated the impact of the natural disasters on the economy. Noy's findings indicated that when a country is less economically developed or less mature, the impact

\footnotetext{
${ }^{2}$ Cavallo and Noy (2011) summarized a wide range of previous studies in this field.
} 
of a natural disaster was more serious and more persistent.

Several studies have analyzed the long-term impact of natural disasters. Noy and Nualsri (2011) reported that a natural disaster has a negative economic impact in the long and short term. In contrast, Skidmore and Toya (2002) reported that a natural disaster has a positive economic impact in the long term. Skidmore and Toya (2002) pointed out a "creative destruction" effect to support their finding. They explained that a natural disaster eliminates old inefficient industries and encourages new, more efficient industries to arise, thereby contributing to economic growth in the long term. According to the theory, natural disaster-induced creative destruction (Cuaresma, Hlouskova, and Obersteiner, 2008) occurs in developed countries, but not in developing countries. This may be because it is difficult to introduce and disseminate new technologies in developing countries.

Cavallo et al. (2010) showed the difference between the actual economic growth path and the estimated counterfactual growth path that would have been accomplished without a natural disaster and then quantitatively calculated the long-term impact of a natural disaster on economic growth. They found that the long-term impact of natural disasters on economic growth was negligible. Using the same econometric method, DuPont and Noy (2012) estimated the long-term impact of the Hanshin-Awaji Earthquake on per capita GDP for Hyogo Prefecture, which includes the Hanshin and Awaji areas. They reported that the long-term effect was not negligible, finding that the per capita GDP of Hyogo Prefecture would have been higher, by JPY500,000, in 2007 had the 1995 Hanshin-Awaji Earthquake not occurred.

As explained above, the economic impacts of natural disasters have been analyzed in several previous studies. However, most of these studies examined 
economic growth or consumption behaviors in relation to natural disasters, and little attention has been devoted to the impact of natural disasters on the labor market using micro data. Thus, our study, which empirically analyzes the long-term effects of a natural disaster on the wage distribution based on micro data, may contribute to a deeper understanding of the mechanism(s) behind the impacts of natural disasters on the productivity of individual workers.

\section{The Hanshin-Awaji Earthquake}

In this section, we provide a brief overview of the scale of the Hanshin-Awaji Earthquake and the extent of damage inflicted by it. At 5:46 a.m. on January 17, 1995, an earthquake of magnitude 7.3 struck off the coast of the northern part of Awaji Island. The displacement of the fault line that extends from Awaji Island to Mt. Rokko, located beyond Kobe City, caused strong tremors in the areas located along the line.

The Japanese government officially declared the following 10 cities and 10 municipalities in Hyogo Prefecture to be the most severely damaged region. The 10 cities were Kobe City (damage was particularly severe in Suma, Hyogo, Nagata, Nada, and Higashi-Nada wards), Amagasaki City, Itami City, Nishinomiya City, Ashiya City, Takarazuka City, Kawanishi City, Akashi City, Miki City in the Hanshin area, and Sumoto City on Awaji Island. The 10 municipalities were Tsuna Town, Awaji Town, Hokutan Town, Ichinomiya Town, Goshiki Town, Higashiura Town, Midori Town, Seitan Town, Mihara Town, and Nantan Town, all on Awaji Island. The orange-colored area in Figure 1 shows Hyogo Prefecture, including these disaster areas. ${ }^{3}$

Next, we briefly introduce the extent of the damage inflicted by the earthquake.

${ }^{3}$ Outside Hyogo Prefecture, a seismic intensity of 4 on the Japanese scale was recorded in Toyonaka City, Osaka Prefecture. 
The Fire and Disaster Management Agency (FDMA) finalized a report on the status of the damage on May 19, 2006. According to its report, 6,434 people were killed and three persons remained missing, whereas 104,906 houses (accommodating 186,175 households) were destroyed completely, 144,274 houses (accommodating 274,182 households) were destroyed partially, and 269 fires were recorded. ${ }^{4}$ Additionally, much of the infrastructure of the region was destroyed. The FDMA reported that 1,579 public buildings, 7,245 sections of road, and 330 bridges were damaged. Broadcast footage of a toppled section of the Hanshin Expressway's Kobe line shocked many viewers. The Kobe lines of the railways operated by the West Japan Railway Company and private railway companies (Hanshin, Hankyu, and Sanyo), as well as the facilities of municipal subway and bus operators, were also severely damaged, bringing traffic in the region to a standstill. The lifeline infrastructure also sustained significant damage.

\section{Econometric Method}

To estimate the long-term impacts of the 1995 Hanshin-Awaji Earthquake on wage differentials, we investigate the causes of the differences in current wage distributions between disaster victims and non-victims. We used three decomposition methods: those proposed by (i) Oaxaca (1973) and Blinder (1973); (ii) DiNardo, Fortin, and Lemieux (1996) ("DFL”); and (iii) Machado and Mata (2005) and Melly (2006). Using these methods, we decompose the wage differentials into two components: one part explained by the differences in characteristics of the two groups, and the other part capturing the effect of the earthquake.

4 See the Hyogo prefectural government Web site: http://web.pref.hyogo.jp/pa20/pa20_000000015.html 
The wage equation for group $\mathrm{V}$ (victims) and group $\mathrm{N}$ (non-victims) is formulated as:

$$
Y_{g}=X_{g} \beta_{g}+u_{g}, g=V, N
$$

where $\mathrm{Y}$ denotes log hourly wages, $\mathrm{X}$ is a vector of individual characteristics affecting wages (annual income at the time the earthquake occurred, years of schooling, age, and age squared), and $\beta$ is a parameter vector of returns to these characteristics.

Using the Blinder-Oaxaca decomposition, we investigate whether the difference in the mean wage between disaster victims and non-victims arose from differences in the observed characteristics of the two groups or from differences in the "prices" for the observed characteristics of the two groups. Differences in prices refer to differences in the returns to the observed characteristics as a function of whether individuals were victims. For example, do victims with the same educational attainment as non-victims earn a different wage because they were affected by the earthquake? We consider such differences in prices to result from the long-term impacts of the earthquake. The difference in the mean wage between group $\mathrm{V}$ (victims) and group $\mathrm{N}$ (non-victims) can then be written as:

$$
\overline{Y_{V}}-\overline{Y_{N}}=\left(\overline{X_{V}}-\overline{X_{N}}\right) \widehat{\beta_{N}}+\overline{X_{V}}\left(\widehat{\beta_{V}}-\widehat{\beta_{N}}\right)
$$

where the first term on the right side of equation (2) represents the explained component, and the second term indicates the unexplained component. One issue to be considered is that estimates of the effect of the earthquake may be biased if differences in the 
unobserved heterogeneity between $\mathrm{V}$ and $\mathrm{N}$ are not considered. To determine the unbiased effect of the earthquake, we considered the difference in the annual income of $\mathrm{V}$ and $\mathrm{N}$ at the time the earthquake occurred as one of the explained components because this difference captures the difference in the possibly unobserved characteristics between $\mathrm{V}$ and $\mathrm{N}$ before the earthquake.

In addition to annual income at the time the earthquake occurred, we included the following variables as explanatory variables: years of schooling, age, and age squared. Our purpose is to decompose the wage differences between $\mathrm{V}$ and $\mathrm{N}$ into two parts as equation (2) shows. The first term in equation (2) consists of differences in the observed characteristics of the two groups at the time the earthquake occurred, $\left(\overline{\mathrm{X}_{\mathrm{V}}}-\overline{\mathrm{X}_{\mathrm{N}}}\right)$ and $\widehat{\beta_{\mathrm{N}}}$; the second term consists of differences in the prices for the observed characteristics that are explanatory variables, $\left(\widehat{\beta_{\mathrm{V}}}-\widehat{\beta_{\mathrm{N}}}\right)$ and $\overline{\mathrm{X}_{\mathrm{V}}}$. For the purpose of obtaining $\overline{X_{V}}-\overline{X_{N}}$, we used the four variables $X_{g}$ in eq. (1)), which we assumed have not been affected by the earthquake, as explanatory variables.

In contrast, other variables (e.g., length of tenure, years of work experience, and industry type), which could have possibly changed after the earthquake, are omitted from equation (1) as explanatory variables. This allows the effects of variation in these omitted variables on wages to be reflected in the coefficient $\widehat{\beta_{\mathrm{g}}}$. More specifically, the error term $\left(u_{g}\right.$ in equation (1)) may be correlated with the four explanatory variables because the error term includes the omitted variables. By so doing, we attempt to estimate the coefficients that include the effects of the omitted variables (whose variations were outcomes of the earthquake) on wages. That is, we estimate differences of prices for the four explanatory variables in the current labor market between victims and non-victims. 
Next, using the DFL decomposition method, we create the counterfactual wage distribution for victims, assuming that victims and non-victims would earn the same wage if they shared the same observable characteristics:

$$
\mathrm{F}_{\mathrm{Y}_{\mathrm{V}}^{\mathrm{V}}}(\mathrm{y})=\int \mathrm{F}_{\mathrm{Y}_{\mathrm{V}} \mid \mathrm{X}_{\mathrm{V}}}(\mathrm{y} \mid \mathrm{X}) \Psi(\mathrm{X}) \mathrm{dF}_{\mathrm{X}_{\mathrm{V}}}(\mathrm{X})
$$

where $\Psi(X)=\mathrm{dF}_{\mathrm{X}_{\mathrm{N}}}(\mathrm{X}) / \mathrm{dF}_{\mathrm{X}_{\mathrm{V}}}(\mathrm{X})$ is a reweighting factor. The idea of the DFL decomposition method is to replace the distribution of $\mathrm{X}$ of group $\mathrm{V}\left(\mathrm{F}_{\mathrm{X}_{\mathrm{V}}}(\cdot)\right)$ with the distribution of $\mathrm{X}$ of group $\mathrm{N}\left(\mathrm{F}_{\mathrm{X}_{\mathrm{N}}}(\cdot)\right)$ using the reweighting factor $\Psi(\cdot)$. The reweighting factor can be estimated as:

$$
\Psi(\mathrm{X})=\frac{\operatorname{Pr}(\mathrm{X} \mid \mathrm{g}=\mathrm{N})}{\operatorname{Pr}(\mathrm{X} \mid \mathrm{g}=\mathrm{V})}=\frac{\operatorname{Pr}(\mathrm{g}=\mathrm{N} \mid \mathrm{X}) / \operatorname{Pr}(\mathrm{g}=\mathrm{N})}{\operatorname{Pr}(\mathrm{g}=\mathrm{V} \mid \mathrm{X}) / \operatorname{Pr}(\mathrm{g}=\mathrm{V})} .
$$

To estimate $\operatorname{Prob}(g=\mathrm{N} \mid \mathrm{X})$, we pooled the two groups and then estimated the probability of an individual belonging to group $\mathrm{N}$ as a function of $\mathrm{X}$, using a logistic regression model.

The Machado and Mata (2005) decomposition method allows decomposing the wage differences between victims and non-victims into explained differences and unexplained differences at each quantile of the wage distributions, which is similar to the Blinder-Oaxaca approach that decomposes the difference in the mean wage.

The decomposition is undertaken based on a counterfactual distribution of $\mathrm{Y}_{\mathrm{V}}$. This is defined as the distribution of wages for victims that would have prevailed if the labor market environment of victims had been the same as that of non-victims. This counterfactual distribution is denoted by $\mathrm{F}\left(\widetilde{\mathrm{Y}_{\mathrm{V}}} \mid \mathrm{X}_{\mathrm{V}}, \widehat{\beta_{\mathrm{N}, \theta}}\right)$, where $\widetilde{\mathrm{Y}_{\mathrm{V}}}$ are generated 
values of $\mathrm{Y}_{\mathrm{V}}$, and $\widehat{\beta_{\mathrm{N}, \theta}}$ are the $\theta^{\text {th }}$ quantile regression coefficients estimated by quantile regression using the sample of non-victims.

The steps in the Machado and Mata (2005) algorithm to construct $\mathrm{F}\left(\widetilde{\mathrm{Y}_{\mathrm{V}}} \mid \mathrm{X}_{\mathrm{V}}, \widehat{\beta_{\mathrm{N}, \theta}}\right)$ are as follows:

1. For each quantile $\theta=0.01,0.02, \ldots, 0.99$, we estimate the quantile regression vector of coefficients $\widehat{\beta_{\mathrm{N}, \theta}}$ for the sample of non-victims.

2. We use the sample of victims to generate fitted values $\widetilde{\mathrm{Y}_{\mathrm{V}}}=\widehat{\beta_{\mathrm{N}, \theta}} \mathrm{X}_{\mathrm{V}}$. For each $\theta$, this generates $\mathrm{N}^{\mathrm{V}}$ fitted values, where $\mathrm{N}^{\mathrm{V}}$ is the sample size of the victims. Next, we randomly select $\mathrm{s}=100$ elements of $\widetilde{\mathrm{Y}_{\mathrm{V}}}(\theta)$ for each $\theta$ and stack these into a $99 \times 100$ element vector $\widetilde{Y_{V}}$. The c.d.f. of these values is the counterfactual distribution for victims.

3. We compare the counterfactual distribution with the actual wage distribution of victims and non-victims.

The wage difference at the $\theta^{\text {th }}$ quantile can be decomposed as follows:

$$
\mathrm{Y}_{\mathrm{N}}(\theta)-\mathrm{Y}_{\mathrm{V}}(\theta)=\left[\mathrm{Y}_{\mathrm{N}}(\theta)-\widetilde{\mathrm{Y}_{\mathrm{V}}}(\theta)\right]+\left[\widetilde{\mathrm{Y}_{\mathrm{V}}}(\theta)-\mathrm{Y}_{\mathrm{V}}(\theta)\right]
$$

The first bracket on the right side of equation (5) represents the explained component at the $\theta^{\text {th }}$ quantile. The second bracket indicates the unexplained component, which presents the true effect of the earthquake, at the $\theta^{\text {th }}$ quantile.

Melly (2006) proposed another estimator that is numerically identical to that 
used by Machado and Mata (2005) if the simulations used in the latter procedure are repeated to infinity. Melly’s estimator is faster to compute and can be used to bootstrap results to provide standard errors. Thus, we used the procedure proposed by Melly (2006).

\section{Data}

We conducted a unique online survey developed exclusively for our project with assistance from Nikkei Research Co. First, we conducted a nationwide screening survey, followed by the main survey. The questionnaires for the main survey were delivered to targeted individuals based on the population distribution revealed by the screening survey. Responses were collected between March 15, 2012 and March 23, 2012. Demographic and regional adjustments were made for the sample layout and allocation, such as prefectures, municipalities, gender, and age.

The survey targeted two types of individual, aged from 20 to 80 years, who lived in Japan as of March 15, 2012: (i) individuals who lived in any of the 10 cities or 10 municipalities in Hyogo Prefecture in January 1995 that were recognized officially as disaster areas by the government, and (ii) individuals who lived in Yokohama City in Kanagawa Prefecture or in Osaka City, Suita City, Takatsuki City, or Sakai City in Osaka Prefecture. Group (i) includes both disaster victims and non-victims. Group (ii) consists only of non-victims.

We used the extent of housing damage to identify victims and non-victims. We asked respondents about the extent of housing damage caused by the earthquake. Participants were asked to choose from the following: (1) own house collapsed completely or was completely destroyed by fire, (2) own house collapsed partially or 
was partially destroyed by fire, (3) own house was damaged only partially (rather than collapsed), or (4) own house was not damaged at all.). ${ }^{5}$ Those who responded with (1) or (2) were defined as disaster victims, and the rest were considered non-victims.

We considered two approaches to identifying treatment and control groups. The first involved confining our sample to group (i) and defining victims as the treatment group and non-victims as the control group. An alternative approach involved including both groups (i) and (ii) and defining victims in group (i) as the treatment group and non-victims in both groups (i) and (ii) as the control group. We considered it appropriate to treat non-victims in group (ii) as the control group because the individuals in this group resembled those living in the disaster area in terms of economic, sociological, and cultural characteristics. More specifically, residents of Yokohama city were chosen to be the control group because of this city's similarity to the disaster areas with regard to its industrial profile. Likewise, residents of selected cities in Osaka Prefecture were treated as the control group because these cities are geographically proximate to the disaster regions, which means that workers in both regions belong to the same labor market. Thus, we defined all members of groups (i) and (ii) as the "whole sample" and members of only group (i) as the "subsample."

In total, we collected 10,387 valid responses: 6,650 from the 10 cities and 10 municipalities (the Hanshin and Awaji areas), 1,646 from Yokohama City, 1,316 from Osaka City, 203 from Suita City, 216 from Takatsuki City, and 356 from Sakai City. The blue-colored area in Figure 1 is Kanagawa Prefecture, which includes Yokohama City, and the green-colored area is Osaka Prefecture, which includes Osaka City, Suita City, Takatsuki City, and Sakai City. The outline of the survey is provided in the Appendix.

5 “Own” houses included both owner-occupied and rented houses. 
We restricted our sample to those who worked at the time of the 1995 Hanshin-Awaji Earthquake and at the time when the survey was conducted because we needed data on annual income in 1994 to control for unobserved heterogeneity as mentioned in the previous section. Furthermore, because we asked respondents about their annual income at the time the quake occurred, in January 1995, the annual income before the quake reflected respondents' income in 1994. Similarly, because we conducted the survey in March 2012, the annual income at the time the survey was conducted was the respondents' income in 2011. Annual income was categorized as follows: zero, less than $¥ 1$ million (equivalent of $\$ 12,149.21^{6}$ ), $¥ 1-2$ million, $¥ 2-4$ million, ¥4-6 million, ¥6-8 million, ¥8-10 million, ¥10-12 million, ¥12-14 million, more than $¥ 14$ million, and unknown/forgotten. Finally, we restricted our sample to those who worked more than 35 hours per week at the time the survey was conducted.

Table 1 presents basic statistics for workers by gender. Hourly wages were calculated by dividing annual income by number of working hours. We used the median values of the categorical choices to recode the annual income in 2011, and working hours were calculated by multiplying the weekly working hours reported in the survey by 52 weeks in a year. The left columns of Table 1 summarize the basic statistics for male workers. The mean hourly wage for victims was $¥ 2,292.69$ (\$27.85), which is lower than the corresponding mean hourly wage for non-victims in the whole sample (¥2560.70 (\$31.11)). Similarly, the mean log hourly wage for victims was lower than that for non-victims living in the Hanshin and Awaji areas (¥2516.50 (\$30.57)). This indicates that victims earned less than non-victims, on average, even 17 years after the

\footnotetext{
${ }^{6}$ Annual incomes and hourly wages in this section were converted at 82.3099 Japanese Yen to 1 US dollar. This exchange rate was the closing price on March 23, 2012, when our online survey was completed.
} 
earthquake.

The right columns of Table 1 present basic statistics for female workers. The mean wage for victims was lower than was that for non-victims in the whole sample (¥1549.24 (\$18.82) vs. ¥1654.49 (\$20.10)). Furthermore, the mean wage of victims was lower than was that of non-victims in the Hanshin and Awaji areas (¥1661.98 (\$20.19)). Similar to the case of male workers, the earnings of victims remained lower than that of non-victims, on average, some 17 years later.

\section{Estimation Results}

We begin with results of the Blinder-Oaxaca decomposition of the wage difference for males. The upper panel of Table 2 shows the results using the whole sample (both groups (i) and (ii)), and the lower panel shows the results using samples restricted to Hanshin-Awaji area (group (i) only). First, wage differences for male workers are summarized in the left columns. The mean wage of disaster victims was lower than that of non-victims by 0.129 log points. The composition explained by the differences in observed characteristics is -0.068 log points, and the unexplained component is -0.060 log points. This indicates that the 1995 Hanshin-Awaji Earthquake still had a negative impact on the wages of male workers 17 years after the earthquake. When we restricted our sample to those who resided in the Hanshin and Awaji areas, the results were unchanged, as shown in the lower panel of Table 2. The mean wage of victims was lower than that of non-victims by 0.111 log points. The explained component is -0.050 $\log$ points, whereas the unexplained component is -0.062 log points. These results are similar to those obtained from the analyses using the whole sample.

Next, we turn to the case of female workers. The upper panel of Table 2 shows 
the results using the whole sample. The mean wage of disaster victims was lower than that of non-victims by 0.052 log points, but the difference was not statistically significant. This indicates that the earthquake had no long-term impact on the 2011 wages of female workers. The results using the subsamples of those who resided in the Hanshin and Awaji areas are shown in the lower panel of Table 2. The mean wage of victims was lower than was that of non-victims, by 0.047 log points. This result is similar to the results obtained from the analyses based on the whole sample. Although the statistically insignificant results may have resulted from the small sample size of female workers, the difference in magnitude and the unexplained component are much smaller than are those of male workers.

Figure 2 shows the results of the DFL decomposition of the wage distribution for males. The upper panel includes two figures showing the wage distributions of the whole male sample. The first figure on the upper left side has two lines: the dashed line represents the actual distribution for victims, whereas the solid line indicates the counterfactual distribution for victims calculated by the DFL method. The counterfactual wage distribution thus captures what the wage distributions would have been, assuming that victims and non-victims obtained the same wage if they shared the same observable characteristics. The solid line is to the right of the dashed line in the middle of each distribution. This means that the victims in the middle quantile of the wage distribution would have earned more had the Hanshin-Awaji Earthquake not occurred. The figure at the upper right has a dashed line representing the actual distribution for non-victims and a solid line indicating the counterfactual distribution for victims, which is identical to the solid line in the left panel. The solid line is very close to the dashed line, suggesting no significant difference in characteristics between 
victims and non-victims. The two figures in the lower panel present the results of the DFL decomposition of the wage distribution for the male subsample residing in the Hanshin-Awaji area. We obtained the same result as with whole sample, in the sense that disaster victims in the middle quantile of the wage distribution suffered the most severe damage from a long-term perspective.

Figure 3 shows the results of the DFL decomposition of the wage distribution for females using the same structure as Figure 2. On the right side, the solid and dashed lines are very close, again suggesting no significant difference in characteristics between victims and non-victims, as was seen in male workers. However, in contrast to the case for male workers, the figures on the left side show no significant difference between the solid and dashed lines. This indicates that the negative impact of the earthquake on the wage distribution of female workers in both the whole sample and the subsample from the Hanshin-Awaji area had already been eliminated when the survey was conducted.

Table 3 presents the results of the Machado-Mata-Melly decomposition of the wage difference in males using the whole sample and the sample restricted to the Hanshin-Awaji area. First, the left columns show the results using the whole sample. At all quantiles, the differences were statistically significant, indicating that the wages of non-victims were higher than were those of victims in all quantiles. The differences were larger at lower quantiles. At the $10^{\text {th }}$ percentile, the wages of disaster victims were lower than were those of non-victims, by $0.166 \log$ points. At the $90^{\text {th }}$ percentile, the wages of disaster victims were lower than were those of non-victims, by $0.067 \log$ points. However, at the $10^{\text {th }}, 20^{\text {th }}$, and $90^{\text {th }}$ percentiles, the unexplained components were not statistically significant. These results indicate that the negative impact of the 
1995 Hanshin-Awaji Earthquake on wages had already been eliminated for low- and high-wage workers. However, the unexplained component was significant for the middle quantile. The unexplained component at the median is $0.078 \log$ points, which is larger than the unexplained component at the mean (0.060 log points), estimated by the Blinder-Oaxaca decomposition. This indicates that the earthquake had a considerable negative impact on the wages of middle-wage workers.

We then restricted the sample to those who resided in the Hanshin and Awaji areas. The right columns of Table 3 present the results. Similar to the left columns, the wage differences were statistically significant in all quantiles, but the unexplained components were significant only in the middle quantiles. The unexplained component at the median (0.081 log points) was larger than that at the mean (0.062 log points).

Table 4 presents the results of the Machado-Mata-Melly decomposition of the wage difference for females. The left columns show the results in the whole sample. In contrast to the case for males, the differences were statistically significant at the $60^{\text {th }}$ percentile and above. Furthermore, the unexplained components were significant at the $80^{\text {th }}$ and $90^{\text {th }}$ percentiles. This indicates that the negative impact of the 1995 earthquake on wages persisted for high-wage females. The right columns of Table 4 present the results using the subsample of Hanshin-Awaji residents. Similar to the left columns of the whole sample, the differences were statistically significant at the $60^{\text {th }}$ percentile and above, whereas the unexplained components were significant only at the $80^{\text {th }}$ and $90^{\text {th }}$ percentiles. The unexplained component at the $90^{\text {th }}$ percentile was 0.138 log points.

\section{Discussion}

In this section, we consider three issues as we discuss and interpret the results. The first 
is the difference in the impact of the earthquake on wage levels by gender. As presented in the previous section, male workers with mid-range wages suffered most from the earthquake, whereas only high-wage female workers were negatively affected. One possible explanation for the difference between genders in the wage levels affected by the earthquake is that the wage distribution of females generally lies to the left of that of males. Table 5 shows the gender gap in hourly wages: indeed, the hourly wages of females in the top quantile are similar to the wages of males in the middle quantile. This indicates that male middle-wage workers and female top-wage workers may, in fact, work in a similar labor environment; these people, who all earned about the same, were all similarly negatively affected by the earthquake.

The second issue is why the earthquake resulted in a reduction in the current wages of people whose houses were damaged by the earthquake 17 years ago. It may seem more likely that losing workplaces due to the earthquake would be related to a reduction in wages. To evaluate the adequacy of our definition of "victims" as those with damaged houses, we conducted the same analysis to examine whether the earthquake affected the wages of victims whose workplaces were damaged by the earthquake. However, we found no long-term negative impact on the wages of those with damaged workplaces after the earthquake. One possible reason that only those whose houses were damaged by the earthquake were negatively affected in terms of wages is that these individuals may have changed their consumption behavior; that is, they may have spent more money to reconstruct their houses and were not able to afford to invest in health and human capital. Such reductions in investment in skills and health may have resulted in a long-term negative effect on their wages. This interpretation is supported by Sawada and Shimizutani (2007) and Sawada and Shimizutani (2008), who 
reported that victims of the 1995 Hanshin-Awaji Earthquake decreased their consumption levels. Another possibility is that when victims moved to other regions after the earthquake, they had to change to new careers that did not match their abilities and skills, which did not enable them to earn as much as they would have if the earthquake had not occurred.

Thus far, we have explained the reasons for the reduction in the wages of disaster victims from a labor-supply viewpoint. One may also ask whether the negative impact on wages may instead be related to a reduction in labor demand after the earthquake. However, it should be noted that both the victims and the non-victims in the whole sample belonged to the same labor market within and near earthquake-damaged areas, with the exceptions of Yokohama City, the Hanshin-Awaji area, and Osaka. Thus, a negative change in labor demand should have affected both victims and non-victims equally. Our findings suggest that the wages of victims were more negatively affected than were those of non-victims given that both victims and non-victims face the same labor-demand conditions.

Finally, we present the characteristics of the middle-wage male victims and the high-wage female victims and discuss why they suffered from long-lasting wage losses. Indeed, the negative effects on middle-wage male victims and high-wage female victims may be explained by their individual characteristics. Table 6 reports the descriptive statistics regarding educational status, the type of employment (employee of private company or organization, government employee, management position, self-employed, family employee in a self-employed business, and unknown/forgotten), and industry. This is summarized by wage level: low-wage $\left(25^{\text {th }}\right.$ percentile and below), middle-wage (between $25^{\text {th }}$ and $75^{\text {th }}$ percentiles), and high-wage (above the $75^{\text {th }}$ percentile) workers. 
One might think the reason that middle-wage males have suffered the most economically is because most of them are self-employed and have businesses that are run from their houses; thus, they may have lost their workplace. However, the left columns of Table 6 indicate that $77.8 \%$ of the middle-wage males were employees of private companies or organizations. This proportion is indeed higher than is those of low-wage males and high-wage males. In contrast, the self-employed accounted for only $6.1 \%$ of the total employment type of middle-wage males, and this proportion is lower than those of low- and high-wage males. Thus, most middle-wage males were employees of private companies/organizations, not self-employed. This shows that the reason for the negative effect on middle-wage males was not due to self-employment and losing both their houses and workplace after the earthquake.

The right columns of Table 6 show the educational status, type of employment, and industrial affiliation of female victims. The proportion of high-wage females who were self-employed was higher than the proportion of low- and middle-wage females who were self-employed, but only $2.8 \%$ of the high-wage group was self-employed. This suggests that self-employment and loss of the house/workplace were also not likely explanations of the negative effect on the wages of high-wage females.

\section{Concluding Remarks}

Three years have passed since the Great East Japan Earthquake struck the eastern part of Japan. It is important to examine the extent to which the earthquake has affected people's lives and its likely long-term impact on the economy. This paper examined a similar large-scale natural disaster in Japan, the 1995 Hanshin-Awaji Earthquake, and estimated its long-term impact on wage distribution. This exercise may facilitate 
anticipation of the long-term impact of the Great East Japan Earthquake.

We collected original data through an Internet survey, which included a range of variables indicating the extent of housing damage, individual characteristics, and annual income, both at the time of the earthquake and when the survey was conducted, for both victims and non-victims of the earthquake.

We summarize our findings as follows. We used three methods to examine how the 1995 Hanshin-Awaji Earthquake has affected the wage distribution: (i) the Blinder-Oaxaca decomposition, (ii) the DFL decomposition, and (iii) the Machado-Mata-Melly decomposition. First, the Blinder-Oaxaca decomposition analysis showed that the 1995 Hanshin-Awaji Earthquake still had a negative impact on the mean wages of male workers 17 years after the earthquake, by $6.0-6.2 \%$, but that its impact had disappeared for female workers. Second, our finding from the DFL decomposition analysis is that the wages of middle-wage workers would have been higher had the 1995 Hanshin-Awaji Earthquake not occurred. This analysis indicated that middle-wage workers were affected most adversely by the earthquake. This result did not hold true for female workers. Finally, similar to the results of the DFL decomposition analysis, the Machado-Mata-Melly decomposition analysis showed that the earthquake had a major negative impact on the wages of middle-wage male workers, and that they would have earned 5.0-8.6\% more had the earthquake not occurred. Additionally, the negative impact of the 1995 earthquake on wages remained for high-wage females, who would have earned $8.3-13.8 \%$ more had the earthquake not occurred.

It is surprising that, although 17 years have passed since the earthquake, the wages of middle-wage male victims and high-wage female victims are still negatively 
affected by the earthquake. These estimated results of the Hanshin-Awaji earthquake can be interpreted in a policy context. It would be expected that low-wage workers would be the victims who suffered most severely from a natural disaster and that they would need more support to recover to pre-disaster levels. However, the results of this study provide an in-depth understanding of the mechanisms underlying the effects of natural disasters on the wage distribution: middle-wage male workers and high-wage female workers were the most negatively affected by Hanshin-Awaji earthquake. We need to formulate long-term recovery plans for middle-wage males and high-wage females to more effectively assist them in recovering from natural disasters, and, in particular, from the Great East Japan Earthquake. 


\section{References}

Blinder, Alan (1973). "Wage Discrimination: Reduced Form and Structural Estimates,” Journal of Human Resources, 8:436-455.

Cavallo, Eduardo, and Noy, Ilan (2011). "Natural Disasters and the Economy: A Survey,” International Review of Environmental and Resource Economics, 5(1):63-102.

Cavallo, Eduardo, Powell, Andrew, and Becerra, Oscar (2010). "Estimating the Direct Economic Damages of the Earthquake in Haiti," Economic Journal, 120(August):F298-312.

Cavallo, Eduardo, Galiani, Sebastián, Noy, Ilan, and Pantano, Juan (2010). “Catastrophic Natural Disasters and Economic Growth,” mimeo, Inter-American Development Bank.

Cuaresma, Jesus C., Hlouskova, Jaroslava, and Obersteiner, Michael (2008). "Natural Disasters as Creative Destruction? Evidence from Developing Countries,” Economic Inquiry, 46(2):214-26.

DiNardo, John, Fortin, Nicole M., and Lemieux, Thomas (1996). "Labor Market Institutions and the Distribution of Wages, 1973-1992: A Semiparametric Approach,” Econometrica, 64:1001-1044.

DuPont, William, and Noy, Ilan (2012). "What Happened to Kobe? A Reassessment of 
the Impact of the 1995 Earthquake in Japan,” SEF Working paper: 09/2012, March 2012, School of Economics and Finance, Victoria University of Wellington.

Machado, José F. and Mata, José (2005). “Counterfactual Decomposition of Changes in Wage Distributions Using Quantile Regression,” Journal of Applied Econometrics, 20:445-465.

Melly, Blaise (2006). "Estimation of Counterfactual Distributions using Quantile Regression,” University of St. Gallen, Discussion Paper.

Noy, Ilan (2009). “The Macroeconomic Consequences of Disasters,” Journal of Development Economics, 97(3):221-31.

Noy, Ilan, and Nualsri, Aekkanush (2011). "Fiscal Storms: Public Spending and Revenues in the Aftermath of Natural Disasters,” Environment and Development Economics, 16(1):113-28.

Oaxaca, Ronald (1973). "Male-Female Wage Differentials in Urban Labor Markets," International Economic Review, 14:693-709.

Ohtake, Fumio, Okuyama, Naoko, Sasaki, Masaru, and Kengo, Yasui (2012) "Measuring the Long-lasting Effect of Natural Disasters: The Case of the 1995 Hanshin-Awaji Earthquake.” mimeo 
Raddatz, Claudio. (2007). “Are External Shocks Responsible for the Instability of Output in Low-Income Countries?” Journal of Development Economics, 84(1):155-87.

Sawada, Yasuyuki, and Shimizutani, Satoshi. (2007). “Consumption Insurance against Natural Disasters: Evidence from the Great Hanshin-Awaji (Kobe) Earthquake,” Applied Economics Letters, 14(4): 303-306.

Sawada, Yasuyuki, and Shimizutani, Satoshi. (2008). "How Do People Cope with Natural Disasters? Evidence from the Great Hanshin-Awaji (Kobe) Earthquake in 1995,” Journal of Money, Credit and Banking, 40.(2-3): 463-488.

Skidmore, Mark, and Toya, Hideki (2002). "Do Natural Disasters Promote Long-run Growth?” Economic Inquiry, 40(4):664-87. 
Table 1. Basic statistics for males

\begin{tabular}{|c|c|c|c|c|c|c|c|c|c|c|c|}
\hline \multirow[b]{2}{*}{ Victims / Non-victims } & \multirow[b]{2}{*}{ Variables } & \multicolumn{5}{|c|}{ Males } & \multicolumn{5}{|c|}{ Females } \\
\hline & & Obs. & mean & s.d. & $\min$ & $\max$ & Obs. & mean & s.d. & $\min$ & $\max$ \\
\hline \multirow[t]{6}{*}{ Victims } & wage & 423 & 2292.69 & 1452.04 & 133.55 & 8413.46 & 139 & 1549.24 & 984.27 & 225.36 & 9615.38 \\
\hline & income & 423 & 613.00 & 341.25 & 75.00 & 1750.00 & 139 & 369.78 & 203.11 & 75.00 & 1750.00 \\
\hline & income in 1995 & 423 & 507.62 & 268.44 & 75.00 & 1750.00 & 139 & 307.91 & 162.16 & 75.00 & 1100.00 \\
\hline & years of schooling & 423 & 14.84 & 2.17 & 9.00 & 21.00 & 139 & 13.76 & 1.93 & 10.50 & 21.00 \\
\hline & age & 423 & 49.28 & 7.71 & 27.00 & 79.00 & 139 & 45.88 & 6.50 & 31.00 & 63.00 \\
\hline & working hours & 423 & 55.09 & 16.04 & 35.00 & 108.00 & 139 & 47.99 & 12.92 & 35.00 & 108.00 \\
\hline Non-victims & wage & 2029 & 2560.70 & 1442.67 & 144.23 & 8856.28 & 544 & 1654.49 & 984.77 & 240.39 & 8413.46 \\
\hline \multirow[t]{5}{*}{ (Whole sample) } & income & 2029 & 665.16 & 346.10 & 75.00 & 1750.00 & 544 & 399.95 & 251.03 & 75.00 & 1750.00 \\
\hline & income in 1995 & 2029 & 560.50 & 257.72 & 75.00 & 1750.00 & 544 & 327.07 & 185.79 & 75.00 & 1750.00 \\
\hline & years of schooling & 2029 & 14.80 & 2.10 & 9.00 & 21.00 & 544 & 14.05 & 1.96 & 9.00 & 21.00 \\
\hline & age & 2029 & 49.60 & 7.00 & 21.00 & 79.00 & 544 & 46.23 & 6.50 & 23.00 & 72.00 \\
\hline & working hours & 2029 & 52.62 & 14.72 & 35.00 & 108.00 & 544 & 47.09 & 11.62 & 35.00 & 108.00 \\
\hline Non-victims & wage & 1101 & 2516.50 & 1404.84 & 144.23 & 8856.28 & 311 & 1661.98 & 1020.50 & 244.46 & 8413.46 \\
\hline \multirow[t]{5}{*}{ (Hanshin-Awaji area) } & income & 1101 & 651.66 & 337.19 & 75.00 & 1750.00 & 311 & 402.17 & 257.50 & 75.00 & 1750.00 \\
\hline & income in 1995 & 1101 & 550.18 & 249.87 & 75.00 & 1750.00 & 311 & 317.68 & 203.13 & 75.00 & 1750.00 \\
\hline & years of schooling & 1101 & 14.75 & 2.11 & 9.00 & 21.00 & 311 & 14.05 & 2.00 & 9.00 & 21.00 \\
\hline & age & 1101 & 49.88 & 6.99 & 21.00 & 70.00 & 311 & 46.82 & 6.77 & 23.00 & 72.00 \\
\hline & working hours & 1101 & 52.31 & 14.77 & 35.00 & 108.00 & 311 & 47.05 & 10.73 & 35.00 & 100.00 \\
\hline
\end{tabular}

Note: Table 1 presents basic statistics for workers by gender. Hourly wages were calculated by dividing the annual income by the number of working hours; the unit is Japanese Yen. Income is measured in 10,000 Japanese Yen. The left columns of Table 1 summarize the basic statistics for male workers, and the right columns summarize them for female workers. 
Table 2. Blinder-Oaxaca decomposition of wage differences

\begin{tabular}{|c|c|c|c|c|c|c|}
\hline \multicolumn{2}{|c|}{$\begin{array}{l}\text { Wage differences for } \\
\text { Victims vs. Non-victims }\end{array}$} & \multicolumn{3}{|l|}{ Males } & \multicolumn{2}{|l|}{ Females } \\
\hline \multirow[t]{3}{*}{ Whole sample } & Difference & -0.129 & $* * *$ & $(0.034)$ & -0.052 & $(0.056)$ \\
\hline & Explained & -0.068 & $* * *$ & $(0.017)$ & -0.033 & $(0.028)$ \\
\hline & Unexplained & -0.060 & $* *$ & $(0.030)$ & -0.019 & (0.054) \\
\hline \multirow[t]{3}{*}{ Hanshin-Awaji } & Difference & -0.111 & $* * *$ & $(0.036)$ & -0.047 & $(0.062)$ \\
\hline & Explained & -0.050 & $* * *$ & (0.019) & -0.004 & $(0.032)$ \\
\hline & Unexplained & -0.062 & $*$ & $(0.032)$ & -0.043 & $(0.058)$ \\
\hline
\end{tabular}

Note: The upper panel shows the results using the whole sample, and the lower panel shows the results for the Hanshin-Awaji area. Wage differences for male (female) workers are summarized in the left (right) columns. "Difference" indicates the mean wage differential between disaster victims and non-victims decomposed into "explained” and “unexplained” components. Standard errors are in parentheses. *, **, and $* * *$ indicate significance at 10,5 , and $1 \%$, respectively. 
Table 3. Machado-Mata-Melly decomposition of wage differences for males

\begin{tabular}{|c|c|c|c|c|c|c|}
\hline \multirow[t]{2}{*}{ Males } & \multicolumn{3}{|c|}{ Whole Sample } & \multicolumn{3}{|c|}{ Hanshin and Awaji areas } \\
\hline & Difference & Explained & Unexplained & Difference & Explained & Unexplained \\
\hline Quantile .1 & $0.166^{* * *}$ & 0.112 & 0.054 & $0.154 * * *$ & 0.087 & 0.067 \\
\hline Quantile .2 & $0.152 * * *$ & 0.090 & 0.062 & $0.150 * * *$ & 0.073 & $0.077^{*}$ \\
\hline Quantile .3 & $0.165^{* * *}$ & $0.088 * * *$ & $0.077 * * *$ & $0.155^{* * *}$ & $0.069 *$ & $0.086^{* *}$ \\
\hline Quantile .4 & $0.165 * * *$ & $0.085 * * *$ & $0.079 * * *$ & $0.150 * * *$ & 0.066 & $0.084^{* *}$ \\
\hline Quantile .5 & $0.151^{* * *}$ & $0.073^{* * *}$ & $0.078 * * *$ & $0.136^{* * *}$ & 0.055 & $0.081^{* *}$ \\
\hline Quantile .6 & $0.142 * * *$ & $0.067 * * *$ & $0.075^{* * *}$ & $0.126 * * *$ & 0.049 & $0.078 * *$ \\
\hline Quantile .7 & $0.129 * * *$ & $0.067 * *$ & $0.061^{* *}$ & $0.116^{* * *}$ & 0.047 & $0.070^{*}$ \\
\hline Quantile .8 & $0.111^{* * *}$ & $0.061 * *$ & $0.050^{*}$ & $0.096 * * *$ & 0.040 & 0.056 \\
\hline Quantile .9 & $0.067 * * *$ & 0.048 & 0.019 & $0.049 * * *$ & 0.030 & 0.019 \\
\hline
\end{tabular}

Note: This table presents the results of the Machado-Mata-Melly decomposition of the wage differences for males. The left (right) columns show the results for the whole sample (subsample). "Difference" indicates the wage differential in each quantile between disaster victims and non-victims decomposed into "explained" and "unexplained" components. *, **, and *** indicate significance at 10 , 5 , and $1 \%$, respectively. 
Table 4. Machado-Mata-Melly decomposition of wage differences for females

\begin{tabular}{|c|c|c|c|c|c|c|}
\hline \multirow[t]{2}{*}{ Females } & \multicolumn{3}{|c|}{ Whole Sample } & \multicolumn{3}{|c|}{ Hanshin and Awaji areas } \\
\hline & Difference & Explained & Unexplained & Difference & Explained & Unexplained \\
\hline Quantile.1 & 0.039 & 0.029 & 0.010 & 0.050 & -0.017 & 0.067 \\
\hline Quantile .2 & -0.042 & 0.023 & -0.065 & -0.083 & -0.004 & -0.079 \\
\hline Quantile .3 & -0.038 & 0.019 & -0.057 & -0.057 & -0.002 & -0.055 \\
\hline Quantile .4 & 0.010 & 0.028 & -0.018 & -0.013 & 0.010 & -0.023 \\
\hline Quantile .5 & 0.022 & 0.018 & 0.004 & 0.017 & 0.009 & 0.008 \\
\hline Quantile .6 & $0.063 * *$ & 0.024 & 0.039 & $0.070 *$ & 0.017 & 0.053 \\
\hline Quantile .7 & $0.093^{* * *}$ & 0.032 & 0.060 & $0.108^{* * *}$ & 0.029 & 0.080 \\
\hline Quantile .8 & $0.110^{* * *}$ & 0.027 & $0.083^{*}$ & $0.114^{* * *}$ & 0.026 & $0.088^{*}$ \\
\hline Quantile .9 & $0.160 * * *$ & 0.033 & $0.126 * * *$ & $0.173^{* * *}$ & 0.035 & $0.138 * * *$ \\
\hline
\end{tabular}

Note: This table presents the results of the Machado-Mata-Melly decomposition of the wage differences for females. The left (right) columns show the results of the whole sample (subsample). "Difference" indicates the wage differential in each quantile between disaster victims and non-victims decomposed into "explained" and "unexplained" components. *, **, and *** indicate significance at 10,5 , and $1 \%$, respectively. 
Table 5. Gender differences in wage distribution (unit: Japanese Yen)

\begin{tabular}{rrrrrr}
\hline & \multicolumn{2}{c}{ Whole } & & \multicolumn{2}{c}{ Hanshin-Awaji Area } \\
\cline { 1 - 3 } \cline { 5 - 6 } Percentile & Males & Females & & Males & Females \\
10 & 824.18 & 412.09 & & 805.86 & 412.09 \\
20 & 1246.44 & 721.15 & & 1201.92 & 721.15 \\
30 & 1550.87 & 1068.38 & & 1442.31 & 978.12 \\
40 & 1923.08 & 1282.05 & & 1885.37 & 1254.18 \\
50 & 2243.59 & 1442.31 & & 2206.81 & 1442.31 \\
60 & 2518.32 & 1518.22 & & 2447.55 & 1479.29 \\
70 & 2991.45 & 1814.22 & & 2926.42 & 1797.43 \\
80 & 3461.54 & 2289.38 & & 3461.54 & 2236.14 \\
90 & 4326.92 & 2719.78 & & 4230.77 & 2692.31 \\
\hline Obs & 2824 & 824 & &
\end{tabular}


Table 6. Individual backgrounds of victims

\begin{tabular}{|c|c|c|c|c|c|c|}
\hline & \multicolumn{3}{|c|}{ Males } & \multicolumn{3}{|c|}{ Females } \\
\hline & $\begin{array}{r}\text { Low wage } \\
\text { (25 percentile and } \\
\text { below) }\end{array}$ & $\begin{array}{r}\text { Middle wage } \\
\text { (between } 25 \text { and } \\
75 \text { percentiles) }\end{array}$ & $\begin{array}{r}\text { High wage } \\
\text { (above } 75 \\
\text { percentile) }\end{array}$ & $\begin{array}{r}\text { Low wage } \\
\text { (25 percentile } \\
\text { and below) }\end{array}$ & $\begin{array}{l}\text { Middle wage } \\
\text { (between } 25 \text { and } \\
75 \text { percentiles) }\end{array}$ & $\begin{array}{l}\text { High wage } \\
\text { (above } 75 \\
\text { percentile) }\end{array}$ \\
\hline \multicolumn{7}{|l|}{ Educational status } \\
\hline Lower than high school graduates & $3.7 \%$ & $2.8 \%$ & $2.9 \%$ & $6.3 \%$ & $2.8 \%$ & $0.0 \%$ \\
\hline Equal to and higher than university graduates & $43.0 \%$ & $47.2 \%$ & $69.2 \%$ & $28.1 \%$ & $29.6 \%$ & $30.6 \%$ \\
\hline \multicolumn{7}{|l|}{ Type of employment } \\
\hline Government employee & $4.7 \%$ & $10.8 \%$ & $19.2 \%$ & $0.0 \%$ & $1.4 \%$ & $13.9 \%$ \\
\hline Management position & $1.9 \%$ & $2.8 \%$ & $2.9 \%$ & $0.0 \%$ & $0.0 \%$ & $0.0 \%$ \\
\hline Self-employed & $17.8 \%$ & $6.1 \%$ & $6.7 \%$ & $0.0 \%$ & $1.4 \%$ & $2.8 \%$ \\
\hline Family employee in self-employed business & $11.2 \%$ & $0.9 \%$ & $0.0 \%$ & $6.3 \%$ & $2.8 \%$ & $0.0 \%$ \\
\hline Unknown/forgotten & $0.9 \%$ & $1.4 \%$ & $1.0 \%$ & $0.0 \%$ & $5.6 \%$ & $0.0 \%$ \\
\hline \multicolumn{7}{|l|}{ Industry } \\
\hline Agriculture and related industries & $0.0 \%$ & $0.5 \%$ & $0.0 \%$ & $0.0 \%$ & $0.0 \%$ & $0.0 \%$ \\
\hline Construction & $8.4 \%$ & $6.6 \%$ & $1.0 \%$ & $12.5 \%$ & $1.4 \%$ & $0.0 \%$ \\
\hline Manufacturing & $12.1 \%$ & $21.7 \%$ & $25.0 \%$ & $12.5 \%$ & $23.9 \%$ & $16.7 \%$ \\
\hline Wholesale trade/Retail trade & $16.8 \%$ & $12.7 \%$ & $6.7 \%$ & $12.5 \%$ & $8.5 \%$ & $2.8 \%$ \\
\hline Finance and insurance & $4.7 \%$ & $3.8 \%$ & $7.7 \%$ & $6.3 \%$ & $7.0 \%$ & $5.6 \%$ \\
\hline Real estate & $0.9 \%$ & $2.4 \%$ & $1.0 \%$ & $0.0 \%$ & $8.5 \%$ & $5.6 \%$ \\
\hline Transportation/Telecommunications & $9.3 \%$ & $8.0 \%$ & $3.8 \%$ & $3.1 \%$ & $4.2 \%$ & $0.0 \%$ \\
\hline Utilities & $1.9 \%$ & $0.9 \%$ & $3.8 \%$ & $0.0 \%$ & $0.0 \%$ & $0.0 \%$ \\
\hline Services & $30.8 \%$ & $16.5 \%$ & $10.6 \%$ & $18.8 \%$ & $25.4 \%$ & $22.2 \%$ \\
\hline Education & $3.7 \%$ & $6.1 \%$ & $6.7 \%$ & $3.1 \%$ & $2.8 \%$ & $5.6 \%$ \\
\hline Medical, health care, and welfare & $0.9 \%$ & $5.2 \%$ & $6.7 \%$ & $6.3 \%$ & $9.9 \%$ & $13.9 \%$ \\
\hline Government employee & $1.9 \%$ & $7.1 \%$ & $15.4 \%$ & $3.1 \%$ & $0.0 \%$ & $11.1 \%$ \\
\hline Others & $8.4 \%$ & $8.0 \%$ & $10.6 \%$ & $21.9 \%$ & $5.6 \%$ & $16.7 \%$ \\
\hline Unknown/forgotten & $0.0 \%$ & $0.5 \%$ & $1.0 \%$ & $0.0 \%$ & $2.8 \%$ & $0.0 \%$ \\
\hline
\end{tabular}


Figure 1. Areas used for the analyses

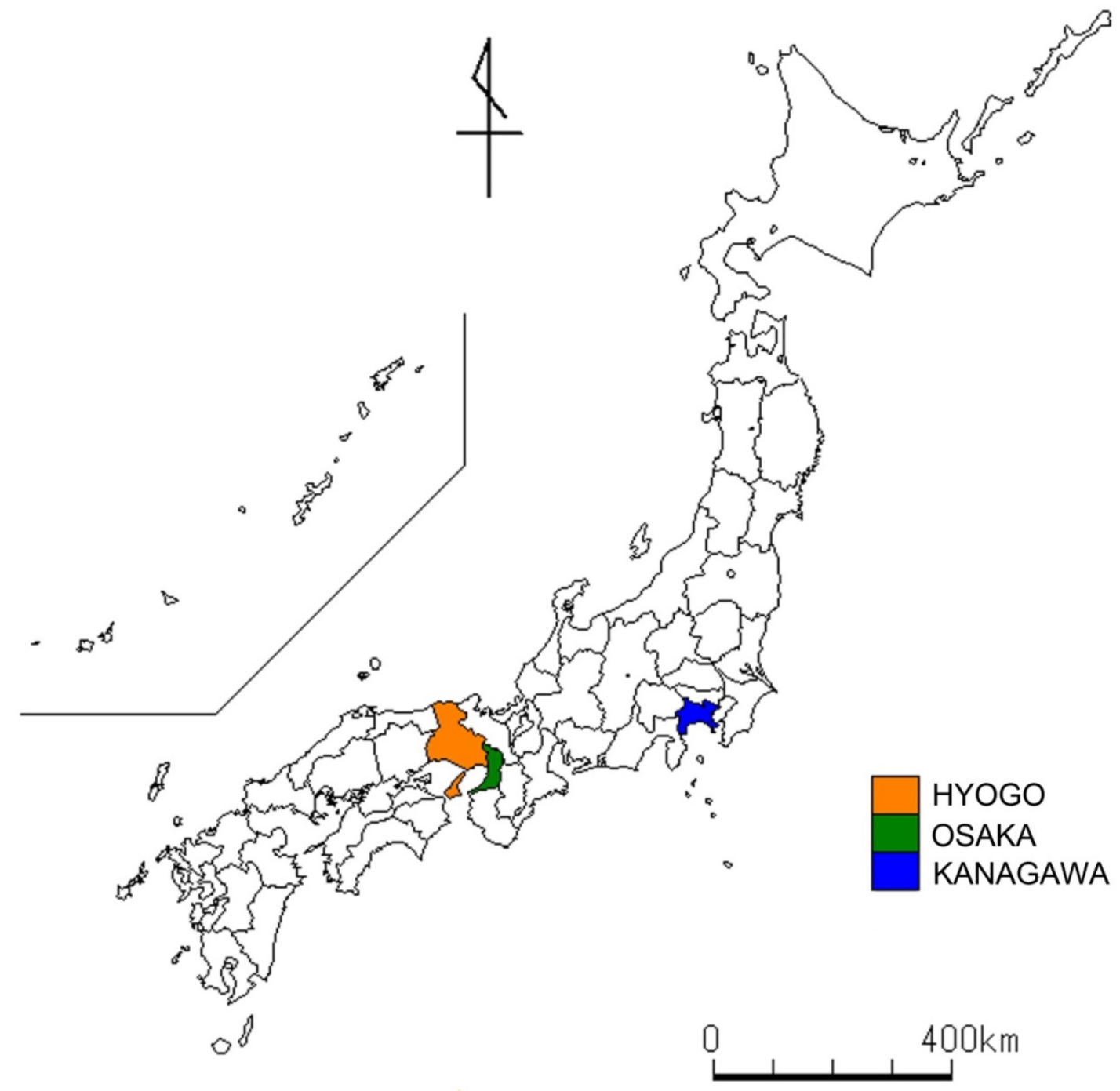

Note: This figure presents a map of Japan. The orange-colored area is Hyogo Prefecture, where the Hanshin-Awaji earthquake struck. This prefecture includes 10 cities and 10 municipalities that the Japanese government officially declared to be the most severely damaged region. The green-colored area is Osaka Prefecture, and the blue-colored is Kanagawa Prefecture. 
Figure 2. DFL decomposition of the wage distribution for males

\section{Males- Whole sample}
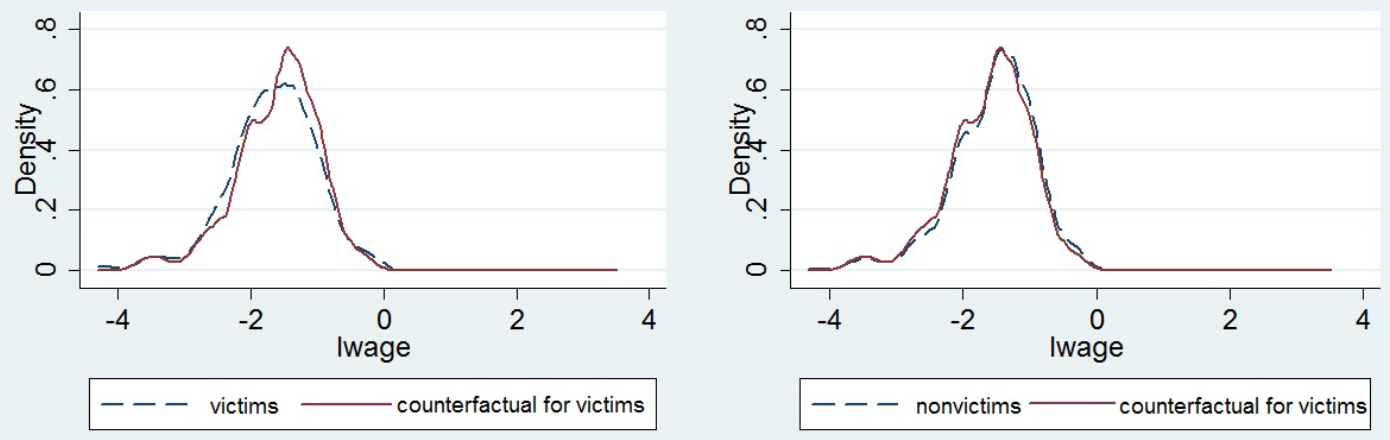

Males- Subsample (Hanshin-Awaji area)
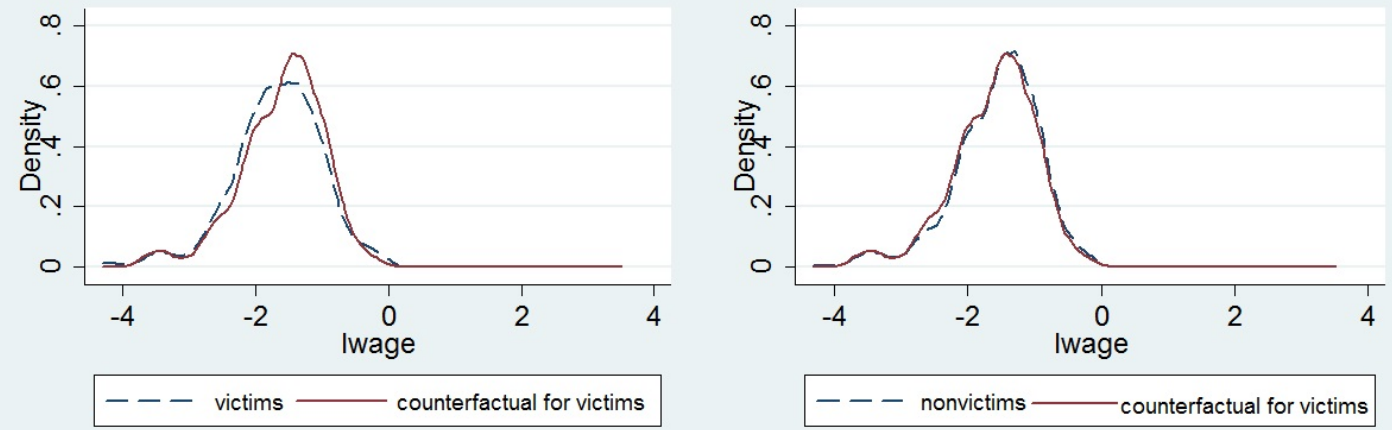

Note: The four figures indicate the wage distributions for male workers. The left figures indicate the actual and counterfactual distributions for victims, and the right figures indicate the actual distribution for non-victims and the counterfactual distribution for victims. The difference between the upper panels and lower panels concerns the sample composition: the upper panels use the whole sample, and the lower panels use the subsample residing in the Hanshin and Awaji areas. In each figure, the dashed line represents the actual distribution for victims or non-victims, whereas the solid line indicates the counterfactual distribution for victims calculated using the DFL method. 
Figure 3. DFL decomposition of the wage distribution for females

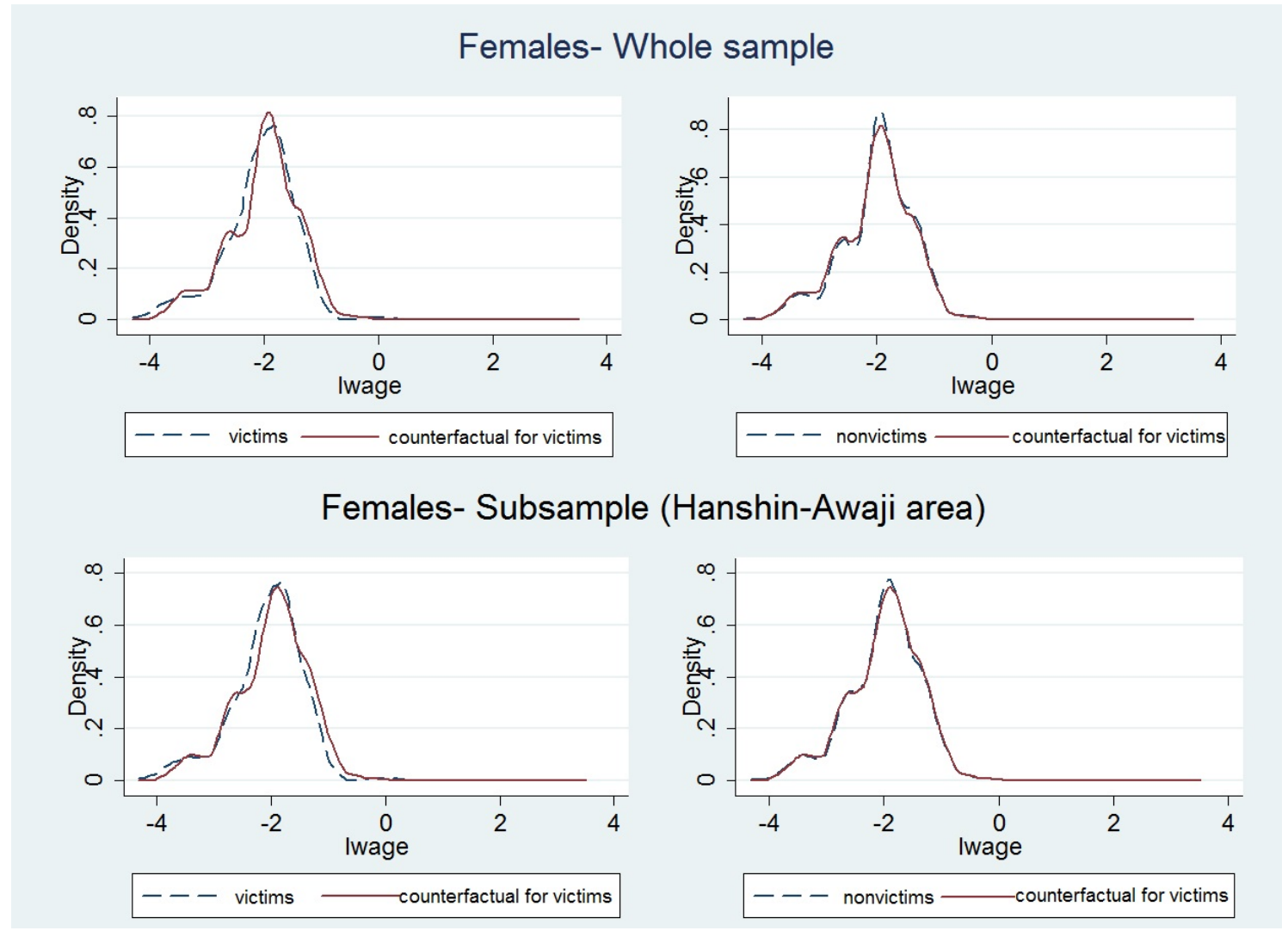

Note: The four figures indicate the wage distributions for female workers. The left figures indicate the actual and counterfactual distributions for victims, and the right figures indicate the actual distribution for non-victims and the counterfactual distribution for victims. The difference between the upper panels and lower panels concerns the sample composition: the upper panels use the whole sample, and the lower panels use the subsample residing in the Hanshin and Awaji areas. In each figure, the dashed line represents the actual distribution for victims or non-victims, whereas the solid line indicates the counterfactual distribution for victims calculated using the DFL method. 


\section{Appendix. Outline of the survey}

\begin{tabular}{|c|l|}
\hline Survey Method & - Internet survey (Nikkei Research. Inc.) \\
\hline Screening & $\begin{array}{l}\text { - A screening survey was conducted across the country before the main survey. Survey questionnaires were } \\
\text { delivered to the targets and responses were collected according to the distribution of the screening survey. }\end{array}$ \\
\hline Regional range & - Nationwide \\
\hline Population & $\begin{array}{l}\text { - Residents in the following municipalities at the time of the earthquake in 1995; Kobe, Itami, Amagasaki, } \\
\text { Ichinomiya-cho, Goshiki-cho, Higahiura-cho, Midori-cho, Nishitan-cho, Mihara-cho, Nantan-cho, } \\
\text { Yokohama, Osaka, Suita, Takatsuki, and Sakai. }\end{array}$ \\
\hline - Males and females aged from 20 to 80 years old who lived in Japan as of March 15, 2012.
\end{tabular}

